\title{
Impact assessment of climate change on the energy performance of the building stocks in four European cities
}

\author{
Yuchen Yang $^{1}$, Kavan Javanroodi ${ }^{1,2}$, Vahid M. Nik ${ }^{1,2,3}$ \\ ${ }^{1}$ Division of Building Technology, Department of Civil and Environmental Engineering, Chalmers University of Technology, \\ Gothenburg, Sweden \\ ${ }^{2}$ Division of Building Physics, Department of Building and Environmental Technology, Lund University, SE- 223 63, Lund, Sweden \\ ${ }^{3}$ Institute for Future Environments, Queensland University of Technology, Garden Point Campus, 2 George Street, Brisbane, QLD, \\ 4000, Australia
}

\begin{abstract}
Many cities are striving to develop urban transformation strategies, in order to transit from traditional city to a sustainable city. Improving the energy efficiency of the existing buildings is the key to address climate change mitigation and adaptation. This paper considers different climate scenarios using different series of future climate in four different European cities, namely, Kiruna, Stockholm, Valencia and Madrid. The study adopts the TABULA database to get access to basic construction information. Energy simulation and data analysis using IDA ICE and MATLAB are performed. Based on climate change, an overall retrofitting plan was developed by combining energy-saving retrofit solutions. The results show that in Madrid and Valencia, future heating demand will decrease and cooling demand will increase. In Kiruna and Stockholm, with the increase of the insulation material, the heating demand of the house has decreased, but the cooling demand has shown a downward trend compared with the cases of Madrid and Valencia. The first reason is the introduction of hybrid cooling, and the second is that the average indoor temperature has been maintained at 21 degrees Celsius due to the low outdoor temperature in summer. The findings indicate that in Kiruna, Stockholm, and Madrid it is better to insulate façades to lower the heating demand in winter. In Valencia, it is possible to have relatively low heating and cooling demand without façades insulation as insulated façades require more cooling demand during summer.
\end{abstract}

\section{Introduction}

Climate change induces increased temperatures and stronger and more frequent extreme events [1]. Europe is expected to experience significant temperature rises in the coming decades [2]. Li et al. assessed the impact of climate change on the global built environment concluded that the decline in heating demand in Central and Northern Europe, such as Finland, Germany, Netherlands and Switzerland [3]. In Sweden, future residential heating demand in Stockholm may drop by $30 \%$ [4]. However, the heating demand still far exceeds the impact of increased cooling demand. Research by Li et al. also suggest that increased cooling demand in the UK could lead to double $\mathrm{CO} 2$ emissions by 2030. In Greece, annual cooling electricity demand grows $3.6-5.5 \%$ [5]. Nik et al conducted a study that assessed possible changes and uncertainties in the future energy performance of the Stockholm residential stock considering 153 buildings over the period of 1961-2100. Four climate uncertainties have been considered: global climate model, regional climate model, emission scenarios and initial conditions The results show that future heating demand will decrease about 30\%lower than before 2011, and cooling demand will increase [4]. Huang et al took Taiwan as an example, a variant method was used to construct the future hour weather year from 2015 to 2100, and EnergyPlus was used to dynamically simulate the annual cooling energy usage in the past and future three time periods. Simulations show that cooling energy increased by $31 \%, 59 \%$, and $82 \%$, respectively, over three time periods. Five passive design strategies for building reconstruction were proposed, and their potentials in mitigating the cooling energy consumption were discussed. The results show that although no single strategy can offset the increase in cooling energy use, a combination of several passive strategies may offset the impact of climate change on

\footnotetext{
* Corresponding author: yuchen.yang@byggtek.lth.se
} 
cooling energy use [6].European countries are advocating retrofitting of buildings to reduce energy demand and carbon dioxide emissions. Energy-efficient retrofitting of buildings is a core strategy to mitigate climate change in these areas and has been identified as a cost-effective method [7] Climate change stimulating the economy and the construction market. Renovating a building is usually an effective investment with long-term expectations, so it is important to consider the adaptability of refurbished buildings to future climates. The retrofitted building should not only provide ideal energy performance for current climate conditions but also maintain a comfortable indoor environment for future climate change.

In this work, the impact of climate change on the energy performance of Stockholm, Kiruna, Madrid, and residential complexes represented by sample buildings was analyzed. Two uncertainties of climate data on energy simulation were also considered, which are two Representative concentration pathways (RCP4.5 and RCP8.5). The building information was obtained from the Tabula web tool. The energy simulation was performed through the IDA ICE simulation program. The simulation period is from 2011 to 2100 . Assess building energy performance by comparing heating /cooling demand and indoor temperature changes in different climate scenarios. At the same time, the paper also puts forward the energysaving retrofitting strategy and evaluates the energysaving retrofitting results.

\section{Methodology}

\subsection{Future climate data sets}

Regional climate models (RCMs) are dynamically downscaling global climate models (GCMs) to the temporal and spatial resolutions suitable for impact assessment and energy simulation. The future weather database used in this work is a synthesized version of RCA4 [8], the fourth generation RCM of the Rossby Centre at Swedish Meteorological Hydrological Institute, with the spatial resolution of $12.5 \mathrm{~km}$ and temporal resolution down to 15 minutes. GCMs that are considered in this work are CNRM, ICHEC, IPSL, HadGEM2and MPI-ESM-LR. More details about synthesizing the weather data sets are available in [9]. All RCMs are enforced by two representative concentration pathways
(RCPs), RCP4.5 and RCP8.5. RCPs are greenhouse gas concentration trajectories used by the IPCC in the 2014 Fifth Assessment Report (AR5) [10].

\subsection{Tabula Web tools}

The Tabula Web tool has been used for the purpose of this study. Tabula Webtool contains information about residential buildings in 13 European countries and their retrofitting. In Spain, the building stock is divided into 4 different building types, mainly classified by age, which are Tipo1-4 single-family houses. There are 6 types of building stock in Sweden, covering single-family houses (SFH1-3) and multifamily houses (MFH 1-3). Tabula mainly focuses on the energy consumption of heating and tap water, without considering cooling, lighting and air conditioning. It should be noted that Tabula does not provide geometric information about the building, therefore the building models are made mainly based on the living area and window area. In this work, models were made and simulated in IDA ICE. Six building models were made for simulation [11]. The total time of simulation is 2011-2100. We divided the 90 years into three time periods, 2011-2040, 2041-2070, and 20712100. The entire study is divided into the following four steps.

Step 1: Set up a reference case based on Tabula.

Step 2: Further simulation of future climate scenarios in IDA ICE.

Step 3: summarize the results according to the number of buildings.

Step 4: Results analysis using MATLAB

An assessment of the U-values for roofs, walls, windows, and floors of exemplary buildings provides an indication of the thermal quality standards established by participating countries over the last century. For seven countries, values are above $2.0 \mathrm{~W} /\left(\mathrm{m}^{2} \mathrm{~K}\right)$ for specific time periods-including southern and central European countries. However, neither of the two Nordic countries has a U-value exceeding $1.0 \mathrm{~W} /\left(\mathrm{m}^{2} \mathrm{~K}\right)$. It should be noted that the assessments do not reflect the actual, but rather assumed U-values derived from the respective national assessment methods. Second, introduce hybrid cooling. Table 1 shows the U-value information of the 4 cities, and the U-value information after renovation. We introduced hybrid cooling in the innovation case. Hybrid cooling, 
when indoor temperature is higher than $24^{\circ} \mathrm{C}$ and outdoor temperature is lower than $24^{\circ} \mathrm{C}$, natural cooling will be used; but if indoor and outdoor temperature is higher than $26^{\circ} \mathrm{C}$, windows will be closed and mechanical cooling system will be used.

Table 1. U-value for base case and renovation cases

\begin{tabular}{|c|c|c|c|c|}
\hline $\begin{array}{c}\text { U- } \\
\text { value[W/(m2K) } \\
]\end{array}$ & Wall & Roof & Floor & Window \\
\hline Madrid & 2.26 & 1.92 & 3.37 & 5.7 \\
\hline Valencia & 2.26 & 1.92 & 3.37 & 5.7 \\
\hline Stockholm & 0.36 & 0.7 & 0.32 & 2.22 \\
\hline Kiruna & 0.2 & 0.7 & 0.21 & 1.97 \\
\hline Renovation & & & & \\
\hline cases & & & & \\
\hline Madrid & 0.45 & 0.45 & 1.44 & 1.8 \\
\hline Valencia & 0.45 & 0.45 & 1.44 & 1.8 \\
\hline Stockholm & 0.1 & 0.39 & 0.23 & 0.76 \\
\hline Kiruna & 0.07 & 0.39 & 0.16 & 0.76 \\
\hline
\end{tabular}

\section{Result and Discussion}

\subsection{Energy result}

This section assesses the heating/cooling demand of buildings and their changes during the period 2011-2100 and analyzes two uncertainties that come from different RCPs. We put five climate data into one box plot to compare the results, each box plot represents one 30-year period. At the same time, this section also compares the changes in the heating/cooling demand for retrofitting cases.

Compared with the beginning of the 21 st century (average 1986-2005), the average global warming of RCP4.5 between 2046 and 2065 averaged $1.4^{\circ} \mathrm{C}$, possibly ranging from 0.9 to $2.0^{\circ} \mathrm{C}$. The temperature increases for 2081-2100 is $1.8^{\circ} \mathrm{C}$ with possible range around1.1-2.6 ${ }^{\circ} \mathrm{C}$. The values for RCP8.5 is $2.0^{\circ} \mathrm{C}$ during the period 2046 2065 with possible range around $1.4-2.6{ }^{\circ} \mathrm{C} .3 .7^{\circ} \mathrm{C}$ during the period 2081-2100 with possible range around 2.6-4.8 ${ }^{\circ} \mathrm{C}$ [12]. There are some similarities between each scenario. All these heralds a warmer future, with the 30year averages in Figure 1 increasing over time. By looking at Figures 1, we can expect that the heating demand will decrease in the future, and the cooling demand may increase.

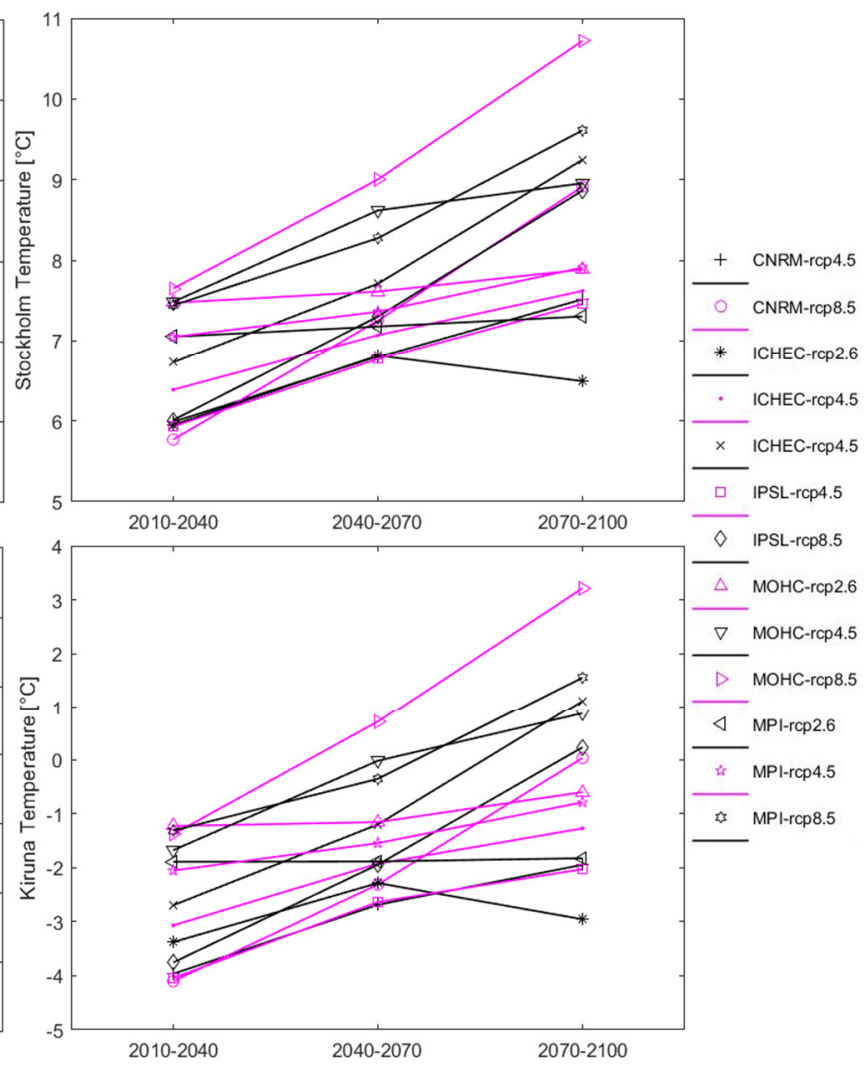

Fig. 1. Average outdoor temperature 


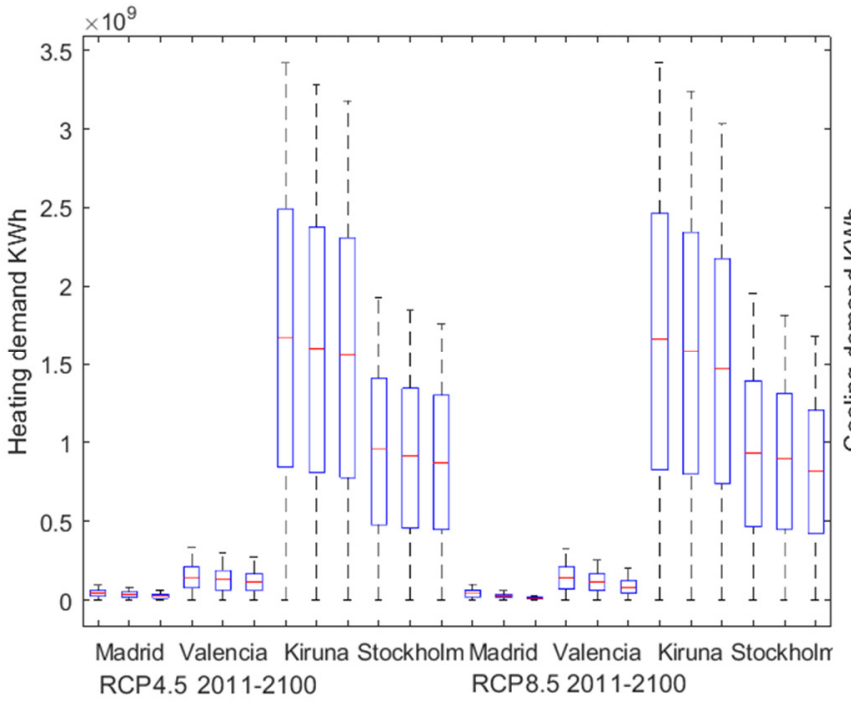

Fig. 2. heating and cooling demand

Figure 2 shows the result of the IDA ICE simulation. Obviously, the heating demand in Spain is much lower than in Sweden. In contrast, cooling demand is much higher than in Sweden. In figure 2 the heating demand in all four cities has shown a downward trend. It can also be seen that compared to RCP8.5 and RCP4.5, Stockholm's heating demand fell by $6 \%$ between 2071 and 2100, and heating demand in Kiruna changed the most between 2071 and 2100 . Reduced by about $10 \%$. In Figure 3 (right), in RCP4.5, cooling demand in Madrid has increased by $1.5 \%$, $2.1 \%$, and $2.4 \%$ every 30 years compared to the previous

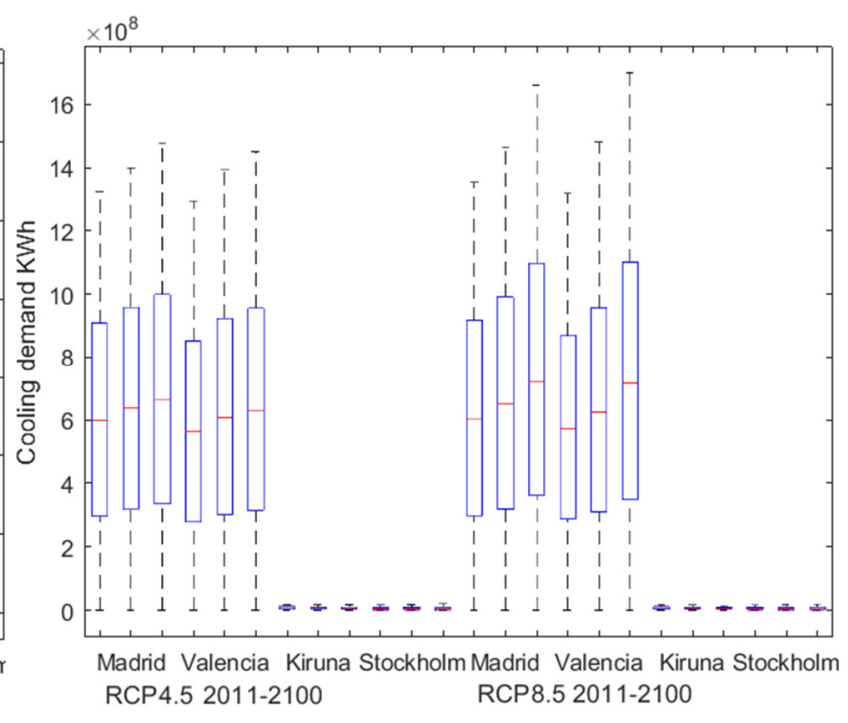

period. In Valencia (Figure 2 right), every 30-years period has increased by about $1.2 \%, 1.7 \%$, and $2.1 \%$ compared to the previous period. In RCP8.5, Madrid has grown by $1.8 \%, 2.8 \%$ and $3.4 \%$ every 30 -years period. In Valencia, the growth rate is about $1.4 \%, 2.1 \%, 3.1 \%$ every 30 years. Comparing RCP4.5 and RCP 8.5, the changes in cooling demand during the first two 30-years periods (2011-2010) were relatively small. In the third 30-years period (20712100) in Madrid, cooling demand RCP8.5 increased by $11 \%$ compared to RCP4.5, and Valencia increased by $9 \%$.

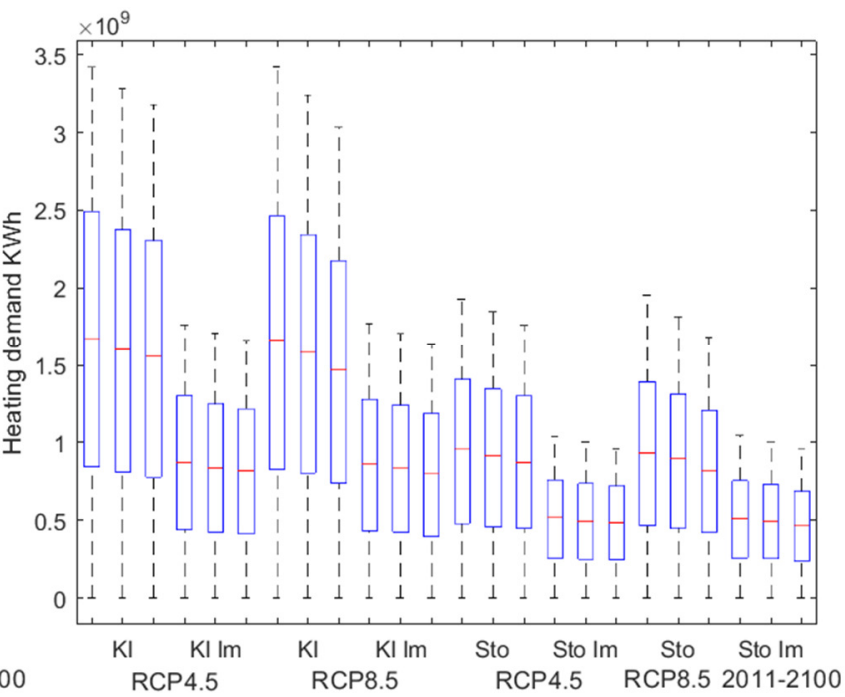

Fig. 3. heating demand for retrofitted cases 
In Figure3 (left) (Im stands for the retrofitted case), we can see that with the change of U-value, the heating demand of Madrid (MA) and Valencia (VA) has a downward trend every 30-years period. Even in extreme carbon emissions scenarios (RCP 8.5), the addition of retrofitted cases will have an impact on heating demand. For example, in the third 30-years period (2071-2100) in Valencia. Compared with the second thirty years (20412070), heating demand decreased by $43 \%$. In the same figure (right), you can see that for Stockholm (Sto) and Kiruna $(\mathrm{KI})$, the increase in insulation materials reduces the heating demand by $43 \%$ to $51 \%$ compared to the previous.

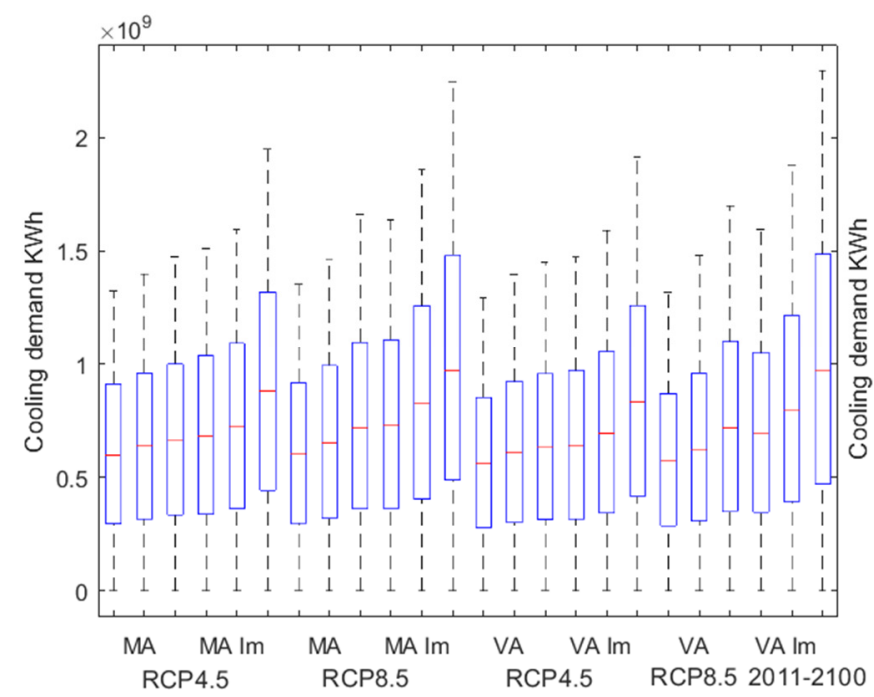

In Figure 4 (left), Im stands for the retrofitted case. When U-value changes (insulation materials are added), under RCP4.5 and RCP8.5, the cooling demand in Madrid (MA) and Valencia (VA) has increased significantly. The most obvious increase is in the third 30-years period (2071-2100). The increase in the RCP8.5 can be seen in the retrofitted case of the third 30-years period. The cooling demand in Madrid is compared to RCP4.5 increased by $16 \%$ and Valencia by $20 \%$. With the increase of insulation materials, the cooling demand increases, and the cooling demand in summer is far greater than the heating demand in winter. In the case of Spain, adding insulation is obviously not a wise move.

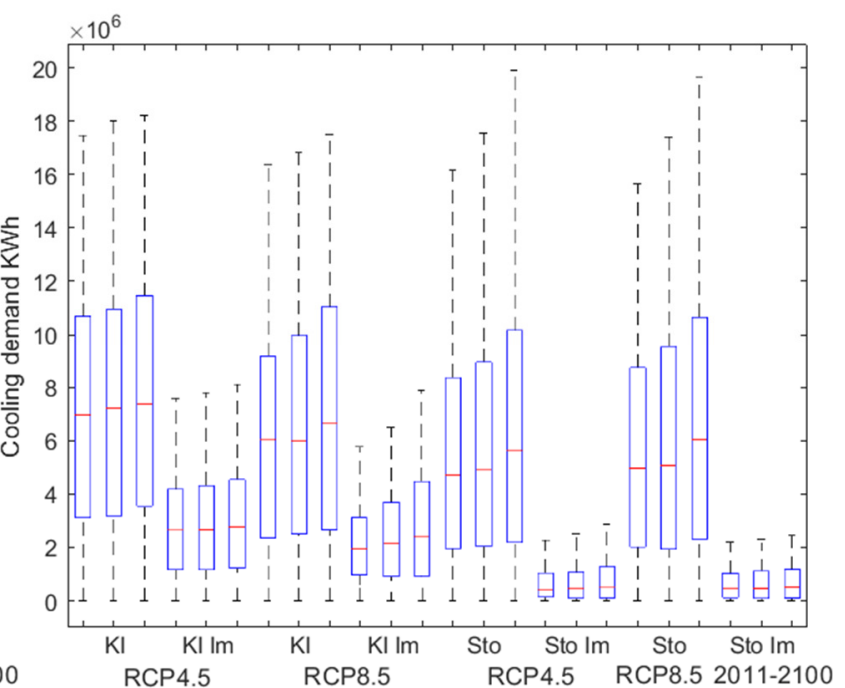

Fig. 4. Heating demand for retrofitted cases (kWh)
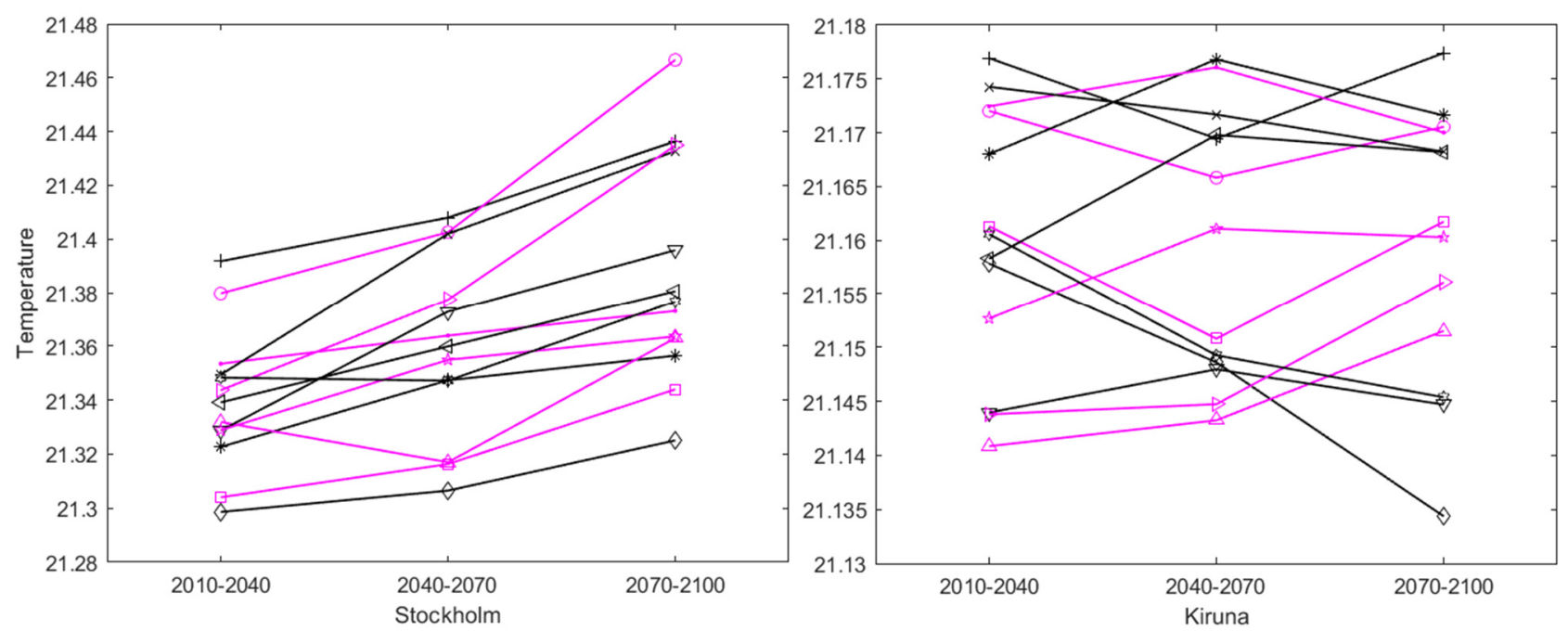

Fig. 5. Indoor temperature $\left({ }^{\circ} \mathrm{C}\right)$ 
Figure 4 (right). Despite the addition of thermal insulation materials, Kiruna and Stockholm have a very significant decline in cooling demand in future climate conditions. The first reason is the addition of Hybrid cooling (natural and mechanical ventilation) in the retrofitted case. When the indoor temperature is higher than $24^{\circ} \mathrm{C}$ and the outdoor temperature is lower than $24^{\circ}$ $\mathrm{C}$, natural cooling is used; however, if the indoor and outdoor temperature is higher than $26^{\circ} \mathrm{C}$, the windows are closed and a mechanical cooling system is used. In real life, the traditional cooling methods of Swedish residential buildings are basically natural cooling[13]. If the tenant feels warm, they will open the window and let the outdoor air cool the room. The second reason can be seen in Figure 5 that the average indoor temperature in Stockholm is 21.3 $\pm 1.2^{\circ} \mathrm{C}$, and the average indoor temperature in Kiruna is in the range of $21.14 \pm 1.4^{\circ} \mathrm{C}$. This means that, despite different RCPs, the indoor temperature will be kept largely within acceptable ranges through natural cooling inside the building. Compared to the case with different RCPs, these two concentration pathways do not significantly affect the indoor temperature distribution even if there is no cooling system in the building.

\section{Conclusion}

In this work, the impact of climate change on the energy performance of Stockholm, Kiruna, Madrid, and residential areas represented by sample buildings was analyzed. Considered uncertainty from two concentration pathways-RCP4.5 and RCP8.5.

As a result, demand for heating decreases with a defined future climate scenario. For example, heating demand between 2071-2100 is 20\% -30\% lower than in 2011. However, despite changes in two RCPs, cooling demand did not increase significantly in the colder Nordic regions. Simulation results show that most of the cooling demand in Northern Europe can be covered by natural ventilation. Although adding insulation materials in Spain reduces the heating demand in winter, the demand for cooling in summer has greatly increased, so for Spain, it is possible to have relatively low heating and cooling demand without façades insulation as insulated façades require more cooling demand during summer.

This study lists possible future trends in building energy consumption in Stockholm, Kiruna, Madrid, Valencia, and provides a reference for future selection of building materials and choices for heating and cooling. Provide more accurate energy use information for each building and provide appropriate guidance for energy use and building designers.

\section{References}

1. IPCC, “Global Warning of $1.5^{\circ} \mathrm{C}, " 2018$.

2. É. Mata, A. Sasic Kalagasidis, and F. Johnsson, "Energy usage and technical potential for energy saving measures in the Swedish residential building stock," Energy Policy, vol. 55, pp. 404-414, Apr. 2013.

3. D. H. W. Li, L. Yang, and J. C. Lam, "Impact of climate change on energy use in the built environment in different climate zones - A review," Energy, vol. 42, no. 1. Elsevier Ltd, pp. 103-112, 2012.

4. V. M. Nik and A. Sasic Kalagasidis, "Impact study of the climate change on the energy performance of the building stock in Stockholm considering four climate uncertainties," Build. Environ., vol. 60, pp. 291-304, Feb. 2013.

5. S. Mirasgedis, Y. Sarafidis, E. Georgopoulou, V. Kotroni, K. Lagouvardos, and D. P. Lalas, "Modeling framework for estimating impacts of climate change on electricity demand at regional level: Case of Greece," Energy Convers. Manag., vol. 48, no. 5, pp. 1737-1750, May 2007.

6. K. T. Huang and R. L. Hwang, "Future trends of residential building cooling energy and passive adaptation measures to counteract climate change: The case of Taiwan," Appl. Energy, vol. 184, pp. 1230-1240, Dec. 2016.

7. É. Mata, J. Wanemark, V. M. Nik, and A. Sasic Kalagasidis, "Economic feasibility of building retrofitting mitigation potentials: Climate change uncertainties for Swedish cities," Appl. Energy, vol. 242, pp. 1022-1035, May 2019.

8. P. Samuelsson, S. Gollvik, C. Jansson, M. Kupiainen, E. Kourzeneva, and W. J. Van De Berg, "The surface processes of the Rossby Centre regional atmospheric climate model (RCA4)," 2015.

9. V. M. Nik, "Making energy simulation easier for future climate - Synthesizing typical and extreme weather data sets out of regional climate models 
(RCMs)," Appl. Energy, vol. 177, pp. 204-226, Sep. 2016.

10. M. Isaac and D. P. van Vuuren, "Modeling global residential sector energy demand for heating and air conditioning in the context of climate change," Energy Policy, vol. 37, no. 2, pp. 507-521, Feb. 2009.

11. I. Ballarini, S. P. Corgnati, and V. Corrado, "Use of reference buildings to assess the energy saving potentials of the residential building stock: The experience of TABULA project," Energy Policy, vol. 68, pp. 273-284, May 2014.

12. M. A. Giorgetta et al., "Climate and carbon cycle changes from 1850 to 2100 in MPI-ESM simulations for the Coupled Model Intercomparison Project phase 5," J. Adv. Model. Earth Syst., vol. 5, no. 3, pp. 572-597, Jul. 2013.

13. V. M. Nik and A. Sasic Kalagasidis, "Impact study of the climate change on the energy performance of the building stock in Stockholm considering four climate uncertainties," Build. Environ., vol. 60, pp. 291-304, Feb. 2013. 